\title{
Emotional Intelligence and its Relationship to Job Burnout among Some Administrative Employees at Al Al-Bayt University
}

\author{
Prof. Iyad M. Hamadneh \\ Dr. Ali K. Nizami \\ Al al-Bayt University, Mafraq \\ Jordan
}

\begin{abstract}
This study aimed at finding out the level of emotional intelligence among the administrative leaders at Al al-Bayt University, and the level of job burnout among their administrative staff, as well as identifying the relationship between emotional intelligence and job burnout among the members of the study sample. To achieve this goal, the Bar-On emotional intelligence scale was applied to a sample of administrative leaders, consisting of 16 deans and center managers, while the job burnout scale was applied to a sample of 184 administrative staff. The findings revealed a high level of emotional intelligence; a low level of job burnout; and a negative correlation between the dimensions of emotional intelligence and the dimensions of job burnout and the overall field of both scale. Finally, the study recommends that the senior administrative leaders (the president and vice-presidents) at Al al-Bayt University take into account the administrative leaders' (deans and center managers) need for emotional intelligence when renewing their assignment or assigning someone else when his/her term ends; in order to keep the least degree of job burnout for their administrative staff.
\end{abstract}

Keywords: Emotional Intelligence, Job Burnout, Administrative Employees.

\section{Introduction}

The direct friction between the administrative leaders and their employees for long practical periods during the official working hours at the university, and the presence of pressures and demands that are not free from the work environment in any way, and the desire of the direct official to implement the policies and decisions of the higher leaders in its various forms and practical applications, may cause what is known as "Job Burnout" (Lopes, Salovey ., \& Straus, 2003, Fan, Cui \& Zhang, 2014). Maslach (1982) defined Burnout as the numbing of inner signals of emotional feelings, as reflected in the inability to create or feel any emotion while Al-Hadeed (2019) viewed the job burnout as a state of physical, emotional, and mental exhaustion associated with the chronic emotional stress that can result from intense, emotionally demanding involvement with people over long periods of time. However, job burnout refers to the result of the accumulation of work-related emotional stress and consists of patterns of an individual's response to work stressors (Maslach \& Leiter, 2016; Steven, 2009). It is important to note that, one of the causes of job burnout arises because of a chronic psychological, when the requirements of work burdened by the individual exceed the capabilities available to him to deal with these pressures .Symptoms include fatigue, loss of motivation, frustration and negative feelings, problems with attention and focus, exposure to more conflicts with others, withdrawal from discussions, and low self-interest (Gerry, 2013). Therefore, job burnout may be the result of severe long-term stresses at work, or the lack of convergence between an individual's expectations and the reality of work, or between emotional work demands and the sources and capabilities of the individual (Fan et al., 2014; Schaufei \& Buunk, 2005).

According to Bakker \& Costa ( 2014) job burnout is usually caused by three factors that the individual has together, namely: work, Lifestyle, and Personality trait. Also, they believe that the chronic exhaustion is the essential component of job burning .Also, job burnout affects employees in terms of withdrawal behavior, such as lateness, justified absence, and turnover. Each component of burnout (emotional exhaustion, depersonalization and reduced personal accomplishment) may result as a consequence of chronic work stress. Emotional exhaustion refers to feeling emotionally drained by intense interactions depersonalization refers to negative or uncaring attitudes toward others and personal accomplishment pertains to a decrease or increase in one's sense of proficiency in working with others (Chan, 2006; Fredrickson, 2001). Furthermore, Smith \& Segal (2014) see job burnout includes a set of non-positive psychological symptoms such as lack of feeling of hope, lack of motivation, feeling of emptiness, negative perception of things, lack of positive interaction, feeling of depression, a greater imbalance in emotions and feelings, and loss of interest in life. 
On the other hand, the university's administrative leaders are the primary engine of the administrative process, the essence of human and administrative interaction between all parties in the university, and interest in their feelings in the so-called Emotional Intelligence that occupies a large part of administrative development research, government, and official policies, with the aim that :They are more effective in their educational institutions (Brackett et al., 2006; Brotheridge \& Grandey, 2002).In the definition of emotional intelligence, researchers are divided into two directions. The first defines emotional intelligence as a set of capabilities that an individual possesses, which stimulates feelings and emotions (Mayer \& Salovey, 1993). As for the second direction, emotional intelligence is defined as a set of characteristics .The personal and social skills necessary for an individual's success in life (Goleman, 1998). Emotional intelligence is simply that we think creatively, and that we use our emotions to solve problems positively (Bar-On, 2006; NasrAldeen, 2010). Mayer et al. (2008) claimed that emotional intelligence involves an individual's ability to perceive, appraise, regulate, understand, and utilize one's own emotions and those of others. Whereas, Bar-On (2006) points out five dimensions of emotional intelligence: Personal dimension, social dimension, adaptation, stress management, and general mood. Emotional intelligence is a very important variable in the personality of the leader, in order to bear all his responsibilities worthily, and he has a strong self-motivation, and this is reflected in his behavior on the one hand and the level of communication and decision-making skills on the other hand. Also, the ability to perceive and understand the emotions of those around him/her. This ability includes not only the awareness of others' feelings, but also the ability to understand body language, facial expression, and tone of voice. Emotional other-awareness is a must for service workers (Goleman, Boyatzis ., \& McKee, 2013; Mills, 2009). This is why it is necessary for an individual to have a high emotional intelligence (Shalah,2015).

Due to the lack of local studies that have addressed emotional intelligence and its relationship to job burnout. The researchers review studies related to emotional intelligence and job burnout, in general, and those related to the relationship between them and another variables; to benefit from their procedures and instruments building and arranged from oldest to newest.

Al-Shahri (2009) study on emotional intelligence and its relationship to decision-making among a sample of public sector employees and the private sector Taif Governorate. The results showed that there is a positive correlation between the degree of overall emotional intelligence and the degree of overall decision-making among members of a sample survey of public sector employees and the private- Taif Governorate.

NasrAldeen (2010) study on the relationship between emotional intelligence and creative thinking among a sample of the first primary grade students who are enrolled and who are not enrolled in kindergarten in Jeddah; the findings showed that there are significant statistical relationship between the average marks of students who enrolled and who not enrolled in kindergarten in: emotional intelligence dimensions (understanding emotions, recognizing emotions, managing emotions and degree college) and innovative thinking dimensions (fluency, flexibility, originality and degree college). Alshammari (2012) conducted a study on the relationship between emotional intelligence and guidance skills of students counselors; scale of emotional intelligence prepared by Hisham Abdallah and Isam Akkad was used, and the scale of guidance skills prepared by Qutaqqa Rashidi was used. Results indicate that emotional intelligence is an effective factor and is indispensable to achieve success in counseling students.

Al- Amarat (2014) conducted a study to investigate the level of emotional intelligence and its relationship with the effectiveness among the leaders of the schools principals at Petra and Wadi Al-Sair directorates in Jordan the researcher used two questionnaires; the first one is to measure the level of emotional intelligence, and the second one is to measure the degree of a leader's effectiveness. The results of the study indicated that the level of emotional intelligence and the leader's effectiveness for the principal of the school was moderate. Shalah (2015) study about the relationship between emotional intelligence and professional performance of psychological counselors in Gaza governorate revealed that, there is a positive correlation between emotional intelligence components and professional performance of psychological counselors in Gaza governorate. Hameedah (2018) study on the relationship between emotional intelligence and innovative thinking among the pupils of the basic stage of the third degree in the state of khartoum revealed that, there is a positive correlation between emotional intelligence and creative thinking among the pupils of the basic stage of the third degree (seventh-eighth) in the state of Khartoum.

Alanezi (2018) conducted a study to measure the impact of internal work environment on the job burnout among nurses working in the hospitals of health ministry in Kuwait. Results indicate that there is a statistically significant effect for both work relationships and administrative communication on job burnout while there in no statistically significant effect of administrative leadership, incentives and physical components on the job burnout. Al Qudah (2018) study about identify the impact of human source management practices on job burnout in King Abdullah University Hospital in Jordan revealed that, there is a statistically significant impact for human sources management practices and for 
career path planning in job burnout; but there is no statistically significant impact for dimensions (training, compensation, safety and security) in job burnout.

Al-Zyout (2018) study on the relationship between job burnout and job satisfaction among workers in the private sector in Jordan; the findings indicate a gap between the levels of job burning out, and the job satisfaction level in term of job conditions, salaries and incentives, justice practices, relations with colleagues and managers.

Finally, Al-Hadeed (2019) study about the level of burnout and the level of self-efficacy and the relationship between the two variables among counselors at Jordanian Badia schools showed that, there is a moderate level of burnout, a high level of self-efficacy, and a negative relationship between burnout and self-efficacy among counselors working at Jordanian Badia schools.

Despite the benefit drawn by the researchers from previous studies regarding current study procedures, on emotional intelligence and job burnout in general, which was almost available, but the researchers could not finding study address the relationship between emotional intelligence and Job Burnout. The study therefore sought to find out the relationship between emotional intelligence and job burnout among some Administrative Employees at Al al-Bayt University.

\subsection{Research Questions}

The study sought to answer the following research questions:

i. What is the level of emotional intelligence among the administrative leaders at Al al-Bayt University?

ii. What is the level of job burnout among the administrative staff at $\mathrm{Al}$ al-Bayt University?

iii. Is there a relationship between emotional intelligence and job burnout among the study participants at $\mathrm{Al}$ al-Bayt University?

\subsection{Significance of the Research}

The significance of the study includes: The lack of studies - exceeding the general limit of the researchers- that interested emotional intelligence of the administrative leaders and its relationship to job burnout among their administrative staff, though there are some studies that interested in emotional intelligence and its relationship with other variables, also some studies that interested in job burnout and its relationship with other variables. The findings of the study will form a basis on which academic researchers can do further studies on emotional intelligence and job burnout in the country. The results of this study might provide decision makers and those interested in job burnout with empirical findings which will enabled them make policy recommendations towards emotional intelligence of the administrative leaders at $\mathrm{Al}$ al-Bayt University. The study will also bridge the gap and variance between those who supported or opposed changing the administrative leaders at Al al-Bayt University.

\subsection{Limitations of the Research}

The study was confined to a sample of male and female administrative leaders (Deans and Center Managers) and a sample of administrative staff at Al al-Bayt University during the second semester of the academic year 2018/2019. Also, the study instruments were limited to Bar-On emotional intelligence scale (Ajwa, 2003) and Taha \& Ragheb (2010) scale; therefore the generalization of its results will be dependent on its validity and reliability indications.

\section{Methodology}

\subsection{Participants}

The study population consisted of all (893) male and female Administrative Employees (administrative leaders and administrative staff) at Al al-Bayt University in Al-Mafraq- Jordan, distributors on 10 faculties; 4 institutes; 3 deanships; and 10 centers (Unpublished statistical issued at $\mathrm{Al}$ al-Bayt University, Jordan).The study used judgmental/purposive sampling method which enabled the research to choose: (16) male and female administrative leaders; and (184) male and female administrative leaders, during the second semester of the academic year 2018/2019. Where only three males were excepted from the sample; because of their absence from work.

\subsection{Instruments}

Depending on previous literature and studies related to emotional intelligence and job burnout in general, the current study used the following two instruments: Bar-On emotional intelligence scale which was translated by Ajwa (2003), as it is one of the well-known model in this field, which has been used by many studies and research in more than one Arab country because of its good psychometric properties.

Bar-On emotional intelligence scale contains of 133 items in the form of short sentences; distributed in 5 composite scales (Intrapersonal, Interpersonal, Stress Management, Adaptability, and General Mood). These composite scales comprise 15 subscale measured emotional intelligence as a mixed ability: Intrapersonal, comprising (self-regard, self- 
awareness, assertiveness, independence, and self-actualization); Interpersonal, comprising (empathy, social responsibility, and interpersonal relationship); Stress Management, comprising (stress tolerance and impulse control); Adaptability, comprising (reality-testing, flexibility, and problem-solving); and General Mood, comprising (optimism and happiness). Response on Bar-On, according to Likert scale ranging from (very seldom or not true of me, to very often true of me or true of me) so that each given numbers (1-5), respectively.

The psychometric properties of the scale have been calculated with several methods; A) Content validity: the scale sentences were presented in their preliminary form to a number of arbitrators (14), who are a group of professors in psychology, psychological counseling, measurement and evaluation. The researchers asked them to express an opinion on the safety of the scale, and the suitability of the linguistic formulation of the Jordanian environment, considering that the scale is ready, and a percentage of agreement (75\%) was adopted between the arbitrators to accept all the scale sentences; B) Internal consistency validity: was estimated by using the internal correlation coefficients for the internal 5 dimensions, as well as their relationship to the overall domain of the scale, at the level of significance $(\alpha<0.01)$ as in Table 2.2.

Table 2.1: Correlation coefficients between Bar-On dimensions, and on the total field of the scale

\begin{tabular}{|l|l|l|l|l|l|l|}
\hline Dimension & Intrapersonal & Interpersonal & $\begin{array}{l}\text { Stress } \\
\text { Management }\end{array}$ & Adaptability & $\begin{array}{l}\text { General } \\
\text { Mood }\end{array}$ & Total \\
\hline Intrapersonal & - & & & & & \\
\hline Interpersonal & $0.69^{*}$ & - & & & & \\
\hline $\begin{array}{l}\text { Stress } \\
\text { Management }\end{array}$ & $0.69^{*}$ & $0.83^{*}$ & - & & & \\
\hline Adaptability & $0.86^{*}$ & $0.71^{*}$ & $0.77^{*}$ & - & & \\
\hline General Mood & $0.79^{*}$ & $0.78^{*}$ & $0.75^{*}$ & $0.78^{*}$ & - & \\
\hline Total & $0.95^{*}$ & $0.86^{*}$ & $0.91^{*}$ & $0.88^{*}$ & $0.86^{*}$ & - \\
\hline
\end{tabular}

* significance at $(\alpha<0.01)$.

Table 2.2 shows that the dimensions are related to each other and to the overall field at the significance level $(\alpha<0.01)$. C) Reliability coefficients of Bar-On scale and its 5 dimensions were estimated, using Cronbach Alpha equation as in Table 2.3.

Table 2.2: Cronbach Alpha coefficients for Bar-On scale and its 5 dimensions

\begin{tabular}{|l|l|}
\hline Dimension & Cronbach Alpha Coefficients \\
\hline Intrapersonal & 0.82 \\
\hline Interpersonal & 0.87 \\
\hline Stress Management & 0.81 \\
\hline Adaptability & 0.59 \\
\hline General Mood & 0.79 \\
\hline Total & 0.73 \\
\hline
\end{tabular}

Table 2.3 shows that Bar-On scale and its 5 dimensions possesses good Reliability at significance level $(\alpha<0.01)$. Furthermore, Reliability coefficients of the 15 subscale Bar-On scale were estimated, using Cronbach Alpha equation as in Table 2.4.

Table 2.3: Cronbach Alpha coefficients for 15 subscale of Bar-On scale

\begin{tabular}{|l|l|l|l|}
\hline Subscale & $\begin{array}{l}\text { Cronbach Alpha } \\
\text { Coefficients }\end{array}$ & Subscale & $\begin{array}{l}\text { Cronbach Alpha } \\
\text { Coefficients }\end{array}$ \\
\hline Self-Regard & 0.56 & Poblem-Solving & 0.59 \\
\hline Assertiveness & 0.72 & Reality-Testing & 0.77 \\
\hline Self-Awareness & 0.81 & Flexibility & 0.59 \\
\hline Independence & 0.80 & Stress Tolerance & 0.65 \\
\hline Self-Actualization & 0.43 & Impulse Control & 0.69 \\
\hline Empathy & 0.64 & Optimism & 0.66 \\
\hline Social Responsibility & 0.69 & Happiness & 0.68 \\
\hline $\begin{array}{l}\text { Interpersonal } \\
\text { Relationship }\end{array}$ & & & \\
\hline
\end{tabular}


Table 2.3 shows that the 15 subscale of Bar-On scale possesses good Reliability at significance level $(\alpha<0.01)$.Job Burnout scale which was constructed by Taha \& Ragheb (2010), has been used in the current study; because of its good psychometric properties. Job Burnout scale contains of 62 items; distributed in 5 dimensions: (psychological and physical exhaustion; satisfaction with co-workers; a sense of reduced accomplishment and loss of personal identity; Work-life imbalance, and social and family accompaniments).Response on Job Burnout scale, according to Likert scale ranging from (strongly disagree to strongly agree) so that each given numbers (1-5), respectively. analysis using the factor analysis of (Principal Component Analysis), data identifying the job burnout-related responses (100) persons from different sectors, according to the statistical program SPSS and the values of (Eigenvalue) were calculated, that there is one factor only increased its eigenvalue (2), which explains which is very high if compared to the underlying eigenvalues of other five factors. Also, a saturated 62 items were kept on the general factor that measure job burnout. Internal consistency validity: was estimated by using the internal correlation coefficients for the internal 5 dimensions, as well as their relationship to the overall domain of the scale, where the correlation coefficients ranged between $(0.294$ to 0.919). Furthermore, Reliability coefficient of the job burnout scale using Cronbach Alpha (0.936), but Cronbach Alpha coefficients for the 5 dimensions of the scale were between (0.648 to 0.883), which means that the scale possesses good Reliability and validity.

\subsection{Procedures}

Administrative leaders and administrative staff at Al al-Bayt University in Al-Mafraq- Jordan in the second semester of the academic year 2018/2019 were determined, and a meeting was held with them to explain the idea of the study. The researchers gave them the instruments of the study to get their responses on each scale.

\subsection{Statistical Analysis}

Data was analyzed using Statistical Package for Social Sciences (SPSS), where means and standard deviations of respondents were computed; t-test was used in answering both first and second research questions, while Pearson correlation coefficient was performed in answering the third question.

\section{Results and Discussion}

3.1 What is the level of emotional intelligence among the administrative leaders at $\mathrm{Al}$ al-Bayt University? Bar-On emotional intelligence scale was applied; T-test was conducted between the means the administrative leaders in the study sample and the theoretical means of the scale. The results were as in Table 3.1.

Table 3.1: Means, standard deviations and T-test of the administrative leaders responses $(\mathrm{N}=16)$ on each dimension of Bar-On emotional intelligence scale

\begin{tabular}{|c|c|c|c|c|c|c|}
\hline No & Dimension & Sample Mean & $\begin{array}{l}\text { Theoretical } \\
\text { Mean }\end{array}$ & $\begin{array}{l}\text { Standard } \\
\text { Deviation }\end{array}$ & $\begin{array}{l}\text { T- } \\
\text { value }\end{array}$ & Sig. \\
\hline 1. & Intrapersonal & 117.73 & 108 & 20.41 & 16.03 & $* *$ \\
\hline 2. & Interpersonal & 101.23 & 84 & 14.37 & 23.81 & $* *$ \\
\hline 3. & Stress Management & 79.94 & 78 & 7.35 & 7.96 & $* *$ \\
\hline 4. & Adaptability & 50.11 & 48 & 16.89 & 17.33 & $* *$ \\
\hline 5. & General Mood & 59.87 & 51 & 25.64 & 24.13 & $* *$ \\
\hline \multicolumn{2}{|c|}{ Total } & 387.16 & 323 & 59.39 & 19.68 & ** \\
\hline
\end{tabular}

Table 3.1 shows that total mean score of the administrative leaders was (387.16), which is higher than the theoretical mean of the instrument as a whole (323), suggesting that findings revealed a high emotional intelligence among the Administrative Leaders at $\mathrm{Al}$ al-Bayt University which is higher than the theoretical average of the scale either on the total score or on the sub-dimensions of it. This might be due to the fact that the administrative leaders are feeling responsible for their work as university administrators and the tasks assigned to them; because it is a job that requires the acquisition of a set of personal, scientific and social skills, in order to be able to handle different personalities and employees in high efficiently. This finding is inconsistent with Shalah (2015). The author reported that psychological counselors in Gaza governorate have a high level of emotional intelligence; on the other hand, this study is not in agreement with the results obtained by Al- Amarat (2014). The authors reported that the principal of the school had moderate emotional intelligence

3.2 What is the level of job burnout among the administrative staff at $\mathrm{Al}$ al-Bayt University? In answering this question, sample means, theoretical means, standard deviations, t-test was used, and results are displayed in Table 3.2. 
Table 3.2: Results of t-test, means and standard deviations on difference between the mean scores of the administrative staff $(\mathrm{N}=\mathbf{1 8 4})$ and the theoretical mean of the job burnout scale, and the sub-dimensions.

\begin{tabular}{|c|c|c|c|c|c|c|}
\hline No & Dimension & $\begin{array}{l}\text { Sample } \\
\text { Mean }\end{array}$ & $\begin{array}{l}\text { Theoretical } \\
\text { Mean }\end{array}$ & $\begin{array}{l}\text { Standard } \\
\text { Deviation }\end{array}$ & $\begin{array}{l}\mathrm{T}- \\
\text { value }\end{array}$ & Sig. \\
\hline 1. & Psychological and Physical Exhaustion & 56.4 & 63 & 6.9 & 11.28 & ** \\
\hline 2. & Satisfaction with Co-Workers & 22.3 & 24 & 0.39 & 118.13 & ** \\
\hline 3. & $\begin{array}{l}\text { Reduced Accomplishment and Loss of } \\
\text { Personal Identity }\end{array}$ & 23.8 & 24 & 1.36 & 28.40 & ** \\
\hline 4. & Work-Life Imbalance & 41.7 & 42 & 0.92 & 64.31 & $* *$ \\
\hline 5. & Social and Family Accompaniments & 13.4 & 15 & 1.64 & 11.05 & $* *$ \\
\hline \multicolumn{2}{|r|}{ Total } & 153.2 & 186 & 24.87 & 8.99 & $* *$ \\
\hline
\end{tabular}

Table 3.2 shows that total mean score of the administrative staff was (153.2), which is less than the theoretical mean of the instrument as a whole (186), suggesting that findings revealed a little job burnout among the administrative staff at $\mathrm{Al}$ al-Bayt University which is less than the theoretical average of the scale either on the total score or on the subdimensions of it. This might be due to work environment, which can be appropriate to their capabilities, skills and job potential, and it is also commensurate with their qualifications, development and administrative courses offered to them from the university's consultancy center. It is taken on this result that we do not know specifically, if the administrative leader will change, will the rate of job burnout?. In addition, they have enjoyed administrative leaders who have a high degree of emotional intelligence and this finding is consistent with results of Al-Hadeed (2019). This finding rhythm well with, Alanezi (2018) which states that nurses working in the hospitals of health ministry in Kuwait have a little job burnout.

3.3 Is there a relationship between emotional intelligence and job burnout among the study participants at Al-alBayt University?. In answering this question, Pearson correlation coefficient was calculated between the administrative leaders responses on the Bar-On scale and the administrative staff responses on the job burnout scale, and on the dimensions of the two scales, and Table 3.3 shows its results.

Table 3.3: Results of Person Correlation Matrix between Bar-On scale and job burnout scale.

\begin{tabular}{|c|c|c|c|c|c|c|c|c|c|c|c|c|}
\hline \multirow{3}{*}{$\begin{array}{l}\text { Emotional } \\
\text { Intelligence }\end{array}$} & \multicolumn{12}{|c|}{ Job Burnout } \\
\hline & \multicolumn{2}{|c|}{$\begin{array}{l}\text { Psychological } \\
\text { and Physical } \\
\text { Exhaustion }\end{array}$} & \multicolumn{2}{|c|}{$\begin{array}{l}\text { Satisfaction with } \\
\text { Co-Workers }\end{array}$} & \multicolumn{2}{|c|}{$\begin{array}{l}\text { Reduced } \\
\text { Accomplishment } \\
\text { and Loss of } \\
\text { Personal } \\
\text { Identity }\end{array}$} & \multicolumn{2}{|l|}{$\begin{array}{l}\text { Work-Life } \\
\text { Imbalance }\end{array}$} & \multicolumn{2}{|c|}{$\begin{array}{l}\text { Social and } \\
\text { Family } \\
\text { Accompaniment } \\
\text { S }\end{array}$} & \multicolumn{2}{|l|}{ Total } \\
\hline & $\begin{array}{l}\text { Correlatio } \\
n \\
\text { Coefficien } \\
t\end{array}$ & $\begin{array}{l}\text { Sig } \\
\text {. }\end{array}$ & $\begin{array}{l}\text { Correlatio } \\
\mathrm{n} \\
\text { Coefficien } \\
\mathrm{t}\end{array}$ & Sig & $\begin{array}{l}\text { Correlatio } \\
\mathrm{n} \\
\text { Coefficien } \\
\mathrm{t}\end{array}$ & $\begin{array}{l}\text { Sig } \\
\text {. }\end{array}$ & $\begin{array}{l}\text { Correlatio } \\
n \\
\text { Coefficien } \\
\mathrm{t}\end{array}$ & Sig & $\begin{array}{l}\text { Correlatio } \\
n \\
\text { Coefficien } \\
\mathrm{t}\end{array}$ & $\begin{array}{l}\text { Sig } \\
\text {. }\end{array}$ & $\begin{array}{l}\text { Correlatio } \\
\mathrm{n} \\
\text { Coefficien } \\
\mathrm{t}\end{array}$ & Sig \\
\hline $\begin{array}{l}\text { Intrapersona } \\
\text { l }\end{array}$ & -0.24 & $*$ & -0.34 & $*$ & -0.47 & $* *$ & -0.37 & $*$ & -0.27 & $*$ & -0.33 & $* *$ \\
\hline $\begin{array}{l}\text { Interpersona } \\
\text { l }\end{array}$ & -0.18 & $*$ & -0.51 & $* *$ & -0.31 & $*$ & -0.31 & $* *$ & -0.41 & $* *$ & -0.46 & $* *$ \\
\hline $\begin{array}{l}\text { Stress } \\
\text { Management }\end{array}$ & -0.35 & $* *$ & -0.52 & $* *$ & -0.30 & $*$ & -0.34 & $* *$ & -0.44 & $* *$ & -0.58 & $* *$ \\
\hline
\end{tabular}

Table 3.3 shows, emotional intelligence had a significant negative correlation with all dimensions of job burnout ( $\alpha$ $<0.01$ ). In addition, job burnout had a significant negative correlation with all dimensions of emotional intelligence. Finlay, the total of Pearson Correlation (-0.947) showed that the higher of emotional intelligence rate among administrative leaders, make a lower level of job burnout among administrative staff. This result is consistent with the theoretical framework and the logical construction of the concept of emotional intelligence and job burnout.

\subsection{Conclusions}

What can be deduced from the results of the current study, in general, is as follows:

1. Administrative Leaders at $\mathrm{Al}$ al-Bayt University have high emotional intelligence. 
2. Administrative Staff at $\mathrm{Al}$ al-Bayt University have little job burnout.

3. As stated, emotional intelligence is one of the factors that can reduce job burnout, and job burnout can reduce job performance, hence every administrative leader should have a high degree of emotional intelligence.

\subsection{Recommendations}

Based on the findings of the current study, the researchers recommend the following:

1. The need to notify those in administrative leaders about the importance of emotional intelligence in job burnout.

2. It is important for senior administrative leadership at Al al-Bayt University to take into account the need for the administrative leader to enjoy emotional intelligence when renewing the leader or assigning someone else when his term ends; In order to keep the least degree of job burnout for their administrative staff.

3. More similar studies be conducted on the relationship between emotional intelligence and job burnout, while including other factors, such as management style and ambition, as well as expanding the study scope to include other universities.

\section{References}

Ajwa, A. (2003). Bar-On scale of emotional intelligence. Iskandriyya, Egyptian Library.

Al- Amarat, M. (2014).The level of emotional intelligence and its relationship with the leader's effectiveness among Jordanian schools. The Jordanian Journal of Educational Sciences, 10(2), 177- 190.

Al Qudah, M. (2018). Impact of human source management practices on job burnout in King Abdullah University Hospital. Master Thesis, Al al-Bayt University, Jordan.

Alanezi, M. (2018). Impact of internal work environment on the job burnout among nurses working in the hospitals of health ministry in Kuwait. Master Thesis, Al al-Bayt University, Jordan.

Al-Hadeed, W. (2019). The self-efficacy and burnout among counselors at Jordanian Badia schools. Master Thesis, Yarmouk University, Jordan.

Al-Shahri, S. (2009). Emotional intelligence and its relationship to decision-making among a sample of public sector employees and the private sector Taif Governorate. Master Thesis, Umm Al-Qura University, Saudi Arabia.

Alshammari, A. (2012). Emotional intelligence and its relationship to guidance skills of students counselors at city of Hail. Master Thesis, Taibah University, Saudi Arabia.

Al-Zyout, Z. (2018). The relationship between the phenomenon of job burnout and job satisfaction among workers in the private sector in Jordan. Master Thesis, Yarmouk University, Jordan.

Bakker, A. \& Costa, P. (2014). Chronic job burnout and daily functioning: A theoretical analysis. Burnout Research, 1, 112-119

Bar-On, R. (2006). The Bar-on model of emotional social intelligence (ESI). Psicothema, 18, 13-25.

Brackett, A., Rivers, S., Shiffman, S., Lerner, N., \& Salovey, P. (2006). Relating emotional abilities to social functioning: A comparison of self-report and performance measures of emotional intelligence. Journal of Personality and Social Psychology, 91, 780- 795.

Brotheridge, C., \& Grandey, A. (2002). Emotional lab our and burnout: Comparing two perspectives of people work. Journal of Vocational Behavior, 60, 17- 39.

Chan, D. (2006). Emotional intelligence and components of burnout among Chinese secondary school teachers in Hong Kong. Teaching and Teacher Education, 22, 1042- 1053.

Fan, D., Cui, L., \& Zhang, M. (2014). Influence of high performance work systems on employee subjective well-being and job burnout: Empirical evidence from the Chinese healthcare sector. The International Journal of Human Resource Management 25(7), 931-950.

Fredrickson, B. (2001). The role of positive emotions in positive psychology: The broaden and build theory of positive emotions. American Psychologist, 56, 218- 226.

Gerry, L. (2013). 10 Signs you are burning out--and what to do about it. http://www.forbes.com/sites/learnvest-signsyoure-burning-out-and-what-to-do-about-it/print/

Goleman, D. (1998). Working with emotional intelligence. New York, NY: Bantam Books.

Goleman, D., Boyatzis, R., \& McKee, A. (2013). Primal Leadership. Boston: Harvard Business School Publishing.

Hameedah, I. (2018). The relationship between emotional intelligence and innovate thinking among the pupils of the basic stage in the state of khartoum. Dissertations, Dar Almandoumah, 9, 1- 22.

Lopes, P., Salovey, P., \& Straus, R. (2003). Emotional intelligence, personality and the perceived quality of social relationships. Personality and Individual Differences, 35, $641-659$.

Maslach, C. (1982). Burnout: the cost of caring. Englewood Cliffs, NJ: Prentice Hall.

Maslach, C., \& Leiter, M. (2016). Understanding the burnout experience: recent research and its implications for psychiatry. Word Psychiatry, 15(2), 103- 110. 
Mayer, J., Roberts, R., \& Barsade, S. (2008). Human abilities: Emotional intelligence. Annual Review of Psychology, $59,507-536$.

Mills, L. (2009). A meta-analysis of the relationship between emotional intelligence and effective leadership. Journal of Curriculum and Instruction, 3 (2), 5-12.

NasrAldeen, E. (2010). Emotional intelligence and its relationship with creative thinking among a sample of the first primary grade students who are enrolled and who are not enrolled in kindergarten in Jeddah. Master Thesis, Umm Al-Qura University, Saudi Arabia.

Schaufei, W., \& Buunk, B. (2005). Burnout: An overview of 25 years of research and theorizing. England, Willy.

Shalah, W. (2015). Emotional intelligence and its relationship with professional performance of psychological counselors in Gaza governorate. Master Thesis, Islamic University, Gaza.

Smith, M., \& Segal, J. (2014). Preventing Burnout. Helpguide.org. http://www.helpguide.org/articles/stress/preventingburnout.htm.

Steven, S. (2009). Emotional intelligence for dummies. Indianapolis: Wily Publishing Inc.

Taha, Faraj., \& Ragheb, Al-Said. (2010) . Job burnout scale. Cairo: The Egyptian Anglo Library. 